\title{
TRATADO DE PAZ ENTRE EL ESTADO COLOMBIANO Y LA FARC COMO MECANISMO GENERADOR DEL PROCESO DE PACIFICACIÓN CON EL ELN
}

\author{
José Javier Nuváez Castillo ${ }^{1}$ \\ Aroldo Eliecer Guardiola ${ }^{2}$
}

\section{Resumen}

Por las particularidades del conflicto interno la conceptualización de la paz en Colombia ha estado enmarcado en negociaciones y acuerdos políticos, sin embargo, su estudio debe estructurarse desde los antecedentes históricos que sobre el concepto se han realizado; por ello este trabajo se centrará en pensar el concepto de paz en Colombia desde un punto de vista teórico y jurisprudencial. En el ámbito mundial, la paz ha venido siendo perseguida como parte de los principios propios de la existencia del hombre, de su diario convivir.

Pero esta realidad no ha resultado fácil de asumir, sobre todo en aquellos espacios donde lo que se pretende es el poder. Tal es el caso de la situación hostil, vivenciada por Colombia, por su estado, por su gente, a través de más de cinco décadas, donde diversos grupos guerrilleros, entre ellos, las Fuerzas Armadas Revolucionarias de Colombia (FARC) y el Ejército de Liberación Nacional (ELN), han pretendido autoridad en ese entorno, pero a través de la presión, la fuerza, el devastamiento de un territorio y de miles de víctimas que han padecido sus consecuencias nefastas. Esa situación, manejada por diversos entes de gobierno, no ha producido logros de solución inmediatos; solo la estrategia militar y de diálogo incipiente ha generado un espacio, un camino para lograr un

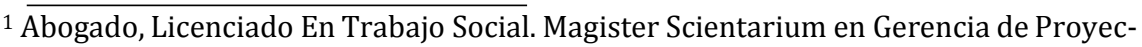
tos de Investigación y Desarrollo. Doctor en Ciencias Políticas, Postdoctor en Integración y Desarrollo de América Latina, Docente Investigador, Facultad de Derecho, Universidad Cooperativa de Colombia (Colombia), Docente en programa de maestría en Derechos Humanos. Miembro grupo de Investigación UCCIDERGRUP, Correo Electrónico: jose.nuvaezc@campusucc.edu.co,jnuvaez@urbe.edu.ve.

${ }^{2}$ Licenciado en Lenguas Modernas. Magister en estudios Políticos y Económicos, Candidato a Doctor en Pensamiento Complejo. Docente Investigador Universidad Cooperativa de Colombia 
tratado, fundamentado en acuerdos políticos, aún con connotaciones incoherentes en ocasiones, pero que deben ser manejadas adecuadamente, dadas las implicaciones políticas, jurídicas, sociales, económicas, culturales surgidas, ante lo cual se requiere canalizar los daños producidos a través del tiempo.

Palabras Clave: Tratado de paz, Estado colombiano, Fuerzas Armadas Revolucionarias de Colombia (FARC), Ejército de Liberación Nacional (ELN), pacificación.

\begin{abstract}
In the world, peace has been pursued as part of the principles of man's existence, of his daily life. But this reality has not been easy to assume, especially in those spaces where the aim is power. Such is the case of the hostile situation experienced by Colombia, by its state, by its people, over more than five decades, where various guerrilla groups, including the Revolutionary Armed Forces of Colombia (FARC) and the National Liberation Army (ELN), have claimed authority in that environment, but through pressure, force, the devastation of a territory and thousands of victims who have suffered its dire consequences.

This situation, managed by different government entities, has not produced immediate solution achievements; only the military strategy and incipient dialogue has generated a space, a way to achieve a treaty, based on political agreements, even with incoherent connotations at times, but which must be managed adequately, given the political, legal, social, economic and cultural implications that have arisen, and to which it is necessary to channel the damages produced over time.
\end{abstract}

Keywords: Peace treaty, Colombian State, Revolutionary Armed Forces of Colombia (FARC), National Liberation Army (ELN), pacification.

\title{
Introducción
}

e propone este estudio, con el fin de analizar el Tratado de Paz entre el Estado Colombiano y la FARC, como mecanismo generador del proceso de pacificación con el ELN. En ello se observa la justificación e importancia de este estudio, dado que se está en un momento propicio en función de resolver una situación por años planteada, por décadas esperada, resultando en tal sentido una temática novedosa. 
Para dar cumplimiento a este cometido investigativo, se examinó el acuerdo firmado entre el gobierno colombiano y la FARC, su referente normativo, como marco para la paz, su contenido implícito acerca del desarrollo agrario, de la pretendida participación política, del aspirado reconocimiento de las víctimas y la asunción de un problema latente gravoso, como lo es el narcotráfico, para su solución; a la vez, se examinan las acciones implementadas buscando la forma de negociación con el ELN, pudiendo concluir en la descripción de sendos resultados del diálogo, con las propuestas de las partes intervinientes en la búsqueda de la pacificación en territorio colombiano.

\section{Metodología}

En este caso de estudio se selecciona el paradigma interpretativo o para- digma cualitativo, el cual se centra en el estudio de los significados de las acciones humanas y de la vida social, según lo expuesto por Martínez (2012). Asimismo, desde el punto de vista de las fuentes de información que sirven de apoyo a este estudio, se enmarca dentro del tipo de estudio documental, según Arias (2012) quien define la investigación documental como “...aquella que se basa en la obtención y análisis de datos provenientes de materiales impresos u otros tipos de documentos" (p.114).

De igual manera, por su contenido, esta investigación se enmarcó dentro de los estudios de tipo jurídico - dogmático. Según Estraño (2009) esta técnica jurídica dogmática reúne los más altos criterios de credibilidad, su originalidad se refleja en el enfoque, criterios, conceptualizaciones, reflexiones, además de ofrecer algunas conclusiones, recomendaciones, en forma de reflexiones finales. Es así que esta técnica se utiliza en revisiones criticas del estado del conocimiento sobre un problema jurídico, integrando, organizando y evaluando la información contenida en las fuentes del derecho, en estudios de derecho comparado para analizar semejanzas, diferencias y tendencias sobre características o problemas jurídicos en el contexto de realidades socioculturales, geográficas o históricas diversas, con fundamento en las fuentes del derecho o en estudios deinvestigación jurídica histórica. 
Por otra parte, en la presente investigación, se emplea un diseño bibliográfico cuyos datos, según Sabino (2010) "se obtienen de fuentes secundarias" (p. 71), es decir, que han sido previamente obtenidos, procesados por otros investigadores. De igual modo, la técnica será la observación documental, de acuerdo con Nava (2002), que es "aquella que se emplea cuando las unidades de observación están constituidas por documentos" (p. 145), aun cuando se hace uso de la observación fáctica, por tratarse de hechos o fenómenos observables.

En lo que respecta a las técnicas de interpretación utilizadas para el análisis de los resultados de la investigación, se acudió a la hermenéutica que significa interpretar, como afirma Martínez (2012), como método utilizado en la investigación científica, pues esta "conlleva necesariamente a una interpretación de los fenómenos estudiados". (p.89). De igual manera, se emplea la técnica del análisis de contenido, la cual según Ander-Egg (2009) "integra diversos recursos que permiten abordar los eventos de estudio, hechos, situaciones, textos, autores, video, cine, con el interés de profundizar en su comprensión” (p. 217).

\section{Análisis del acuerdo de paz entre el gobierno colombiano y la FARC}

Acerca del tratado de paz, se vislumbra como un proceso histórico para la sociedad colombiana, es un anhelo el poder contar con un país en donde los diversos grupos políticos y guerrilleros puedan conciliar mediante acuerdos duraderos, estos esfuerzos se inician en Colombia a mediados de los años ochenta del siglo pasado, tal como lo asevera Chernick (2012), al señalar que

Ya para inicios de la década de los ochenta, en este sentido el país podía ser posicionado a la vanguardia de los esfuerzos realizados en aras de obtener una salida política concertada que permitiera cerrar las hostilidades armadas mediante la adopción de acuerdos negociados (p. 47).

Articulándose así, una progresiva agenda de trabajo con el propósito de lograr acuerdos de paz con los grupos que se encuentran al margen de la 
ley, siendo el más reciente y connotado el acuerdo logrado entre el Estado Colombiano y la FARC, en donde esta organización se le ha permitido como parte del acuerdo, entrar al juego político mediante la posibilidad de participar en elecciones para optar a diversos cargos públicos, se espera así, que Colombia pueda lograr una paz duradera, basada en el acuerdo de paz, el cual sebe ser cumplido a cabalidad entre las partes con el fin de gestar la posibilidad real de ser efectivo en el tiempo.

Es pertinente evocar el proceso de paz vivido en El Salvador, el cual fue firmado el 16 de enero de 1992 en Chapultepec, Ciudad de México, este acuerdo era un cese a la guerra entre la clase política y guerrillera que dominada el país para la época, en este proceso se logró el consenso en base a ocho (8) acuerdos que permitieron trabajar para la consecución del ceso del conflicto armado. La reseña de El Salvador, es pertinente tenerla como referencia en el proceso de paz colombiano, por cuanto al tener claridad y compromiso en la estructuración de una agenda de negociación, los acuerdos logrados deben ser asumidos por las partes involucradas para proyectar la posibilidad de poder contar una paz en el tiempo que le brinde felicidad a la sociedad colombiana.

Por consiguiente, la negociación efectiva entre las partes juega un rol importante en el proceso de paz, de allí que para que esta sea real y valedera, González (2015), plantea que se debe realizar

El enfoque de análisis de coyuntura, que reconoce un horizonte relacional y estratégico de la acción política y comprende la identificación de actores, acontecimientos, escenarios, correlación de fuerzas, relación estructura-coyuntura y periodización es decir, comprende el fenómeno político inscrito en un tiempo histórico específico y socialmente dinamizado por los actores, las fuerzas y las estrategias en contienda. (p. 245).

En este caso, comprender el fenómeno pasa por identificar las razones de la mesa; interpretar el acuerdo inicial firmado por las partes, el cual delimita la dinámica de las negociaciones; entender la reorganización de las fracciones del bloque en el poder que mantienen una oferta por su hegemonía; enmarcar el fenómeno en un contexto internacional favorable a los 
cambios democráticos y el fin de la guerra interna; e inscribir el fenómeno en la correlación de fuerzas sociales establecidas en la coyuntura política. Lo anterior permite identificar las posibilidades de éxito y las limitaciones del proceso de diálogos.

En el caso del acuerdo de negociación de paz suscrito entre el gobierno colombiano y la FARC, se establecieron cinco puntos estratégicos sobre los cuales debía ventilarse el tratado, a saber: un marco normativo específico, pautas para el desarrollo agrario, la participación política, el reconocimiento de las víctimas y la asunción de la solución al problema del narcotráfico; aspectos estos que a la vez se desagregan en muchas variables o aristas correlacionadas.

En tal sentido, el paso del tiempo transcurrido, requiere su análisis, examinando las bases legales sobre las cuales se desarrolla esta tregua entre las partes involucradas, indagar sobre el desarrollo de los aspectos convenidos, que han de ser necesarios tomando en cuenta la secuela que ha traído consigo la intervención de los espacios territoriales colombianos, desde el punto de vista geográfico y de las personas, víctimas de conflicto, pertenecientes a ese ámbito territorial devastado.

Si bien, con el acuerdo suscrito, se orienta la culminación definitiva del peligro armado que azotó a Colombia durante décadas, siendo garantía de tal propósito el cese al fuego (en todas sus connotaciones) entre las partes involucradas. Pero a la vez comporta, la rehabilitación de las FARC-EP, Ejército del Pueblo, a una ciudadanía donde deban ejercer los deberes y derechos consagrados en las leyes vigentes, constituyéndose en agentes productivos a la sociedad colombiana, de acuerdo con sus intereses, y con base en lo planteado en el acuerdo entre Estado y FARC-EP. Prosiguiendo con lo planteado, Olave (2013) expone que

Lo que se dimensiona como "fin del conflicto" cubre espectros distintos de una misma trama de acciones: para las FARC-EP, se trata de una modificación estructural de la organización del Estado y de la sociedad (el conflicto como sistema social en crisis). Pero, para el estado colombiano, se refiere específicamente a la lucha armada guerrillera y al cese de hostilidades entre las fuerzas armadas 
(el conflicto como confrontación bélica). Sobre la base de lo acordado en función de lo que no queda definido (¿qué es el conflicto?) sino implicado desde el discurso de cada actor, la paz se condiciona a la finalización del conflicto. (p. 355).

Desde las visiones planteadas sobre la culminación del conflicto, es preciso que las partes dejen en evidencia los significados otorgados para así, gene- rar el debate que conduzca a interpretaciones asertivas con la finalidad de impedir en el futuro que se tomen acciones sobre la base de subjetividades no clarificadas en el acuerdo de paz, las cuales podrían conducir a roces, brechas, entre las partes, ejerciéndose un peligro estimulante, generador, de nuevos conflictos entre las organizaciones involucradas y el Estado Co- lombiano. Una de estas brechas a considerar es lo planteado por Rodrí- guez (2014), quien afirma que

El tema más difícil, si cabe, de la negociación, es la justicia transicional y la reincorporación a la vida civil de los guerrilleros. Desde luego, la gravedad de los delitos cometidos por la guerrilla el terrorismo, el uso de minas antipersonales y el narcotráfico deben tener algún castigo que resista el escrutinio de la Corte Penal Internacional. (p. 6).

En este sentido, como se ha hecho mención, es pertinente clarificar las interpretaciones que las partes le brindan al cese del conflicto, sobre todo en los puntos más álgidos de la confrontación, esto para velar que exista una clara percepción de cumplir a cabalidad el acuerdo suscrito, evitando la posibilidad de generación de situaciones que puedan entorpecer la conquista de la paz duradera en Colombia.

Por consiguiente, es necesario contar con un balance de lo acontecido desde la firma del acuerdo, noviembre de 2016, a la fecha, ante lo cual, el Observatorio de Seguimiento a la Implementación del Acuerdo de Paz (2018), expone que "se observa muy bajo porcentaje de cumplimiento, cuyos expertos revelaron en enero de 2018 que solo se ha cumplido el 18,3\% de lo acordado" (p. 1). 
Asimismo, en declaraciones de voceros de la presidencia del país, se afirma que la protección de los líderes sociales es su primera prioridad, para lo cual, mediante decretos se crea un nuevo sistema de alertas tempranas, más ágil y eficaz, y se instruye a gobernadores y alcaldes para que, en su condición de agentes del presidente en materia de orden público, prioricen la protección de tales líderes sociales.

No obstante, esto se ha constituido en un reto, pues la matanza de los líderes sociales en la actualidad es abrumadora, convirtiéndose esa violencia en su contra en uno de los puntos negros del posconflicto durante este año; es así que, según la Defensoría del Pueblo de Colombia hay una situación de riesgo persistente, y entre enero de 2016 y julio de 2017, se han registrado 186 homicidios de líderes sociales y defensores de derechos humanos.

Asimismo, en el informe del Alto Comisionado de las Naciones Unidas para los Refugiados (Acnur, 2018) se refleja el asesinato de líderes sociales tras denunciar infinidad de acciones violentas en contra de sus comunidades; medios locales reseñan que fallecieron un grupo de activistas mientras las autoridades afirman que son minoría. Además, se suman excombatientes asesinados y familiares, a quienes el Estado debía brindar protección personal para consolidar su reintegración social como parte de lo pactado.

Por su parte, para las FARC, la implementación del proceso ha sido deficiente y actualmente el proceso enfrenta uno de sus momentos más difíciles luego de la firma del acuerdo. Voceros de esta organización, de acuerdo a declaraciones examinadas en diversas noticias publicadas, han afirmado que la Jurisdicción Especial para la Paz (JEP) fue "desfigurada" en el Congreso y su texto actual no corresponde a lo que se firmó en el Teatro Colón en noviembre de 2016. Sin embargo, la misma Corte Constitucional de Colombia aprobó el sistema de Justicia Especial para la Paz (JEP) como mecanismo para juzgar a excombatientes que formaron parte del conflicto armado, pero será el Congreso quien determine las penas de los mismos.

Ante ello, el gobierno aseguró la posesión de los cargos de los magistrados de la JEP, para iniciar sus labores; sin embargo, a través de un co- 
municado, las FARC lamentó el hundimiento de la reforma política ofertada, de las circunscripciones territoriales especiales de paz, y que aún hayan más de 600 integrantes de las FARC en prisión, y mostraron firmeza al afirmar la imposibilidad de soslayar el acuerdo suscrito, por estarinvestido de constitucionalidad por la Corte Constitucional, y reiteraron su compromiso para continuar con el proceso de paz.

Una revisión de la literatura existente y la diversidad de noticias y declaraciones examinadas muestran un consenso donde se confirma lo planteado acerca de los resultados derivados de la firma del acuerdo de negociación entre la administración del presidente Santos y la organización de las FARC.

Es así que, en primer término, en cuanto a la creación de un nuevo partido político en Colombia, se observa la Fuerza Alternativa Revolucionaria del Común (FARC) que fue el nombre elegido por el ex - grupo insurgente en su Congreso Fundacional para su incursión en la política colombiana, lo cual fue un logro alcanzado y permite a sus miembros optar a cargos políticos mediante elecciones, habiendo presentado en los comicios de 2018 u candidato a la presidencia, que fue eliminado por aparentes razones de salud; pero, a la vez, y presentaron a sus aspirantes para el Senado y la Cámara de Representantes que, según lo acordado con el Gobierno, tendría cinco puestos en cada uno.

En segundo término, se produce una aparente dejación de armas, donde casi siete mil ex - insurgentes entregaron sus armas, lo que tuvo un impacto positivo en el ámbito nacional al disminuir los casos de homicidios y salvar a más de tres mil vidas. En los 281 municipios destinados al postconflicto, se redujo en 27 por ciento casos de muertes violentas. Asimismo, la Misión de la Organización de las Naciones Unidas (ONU, 2017) inhabilitó en septiembre pasado diversas armas de fuego, pistolas, revólveres, fusiles de asalto, fusiles de precisión, escopetas, sub - ametralladoras y ametralladoras, entre otras.

A la vez, según cifras del balance general de implementación del acuerdo por parte del gobierno de Colombia, en este proceso se han entregado casi 9.000 armas, se alcanzó la tasa de homicidios más baja en tres décadas (24 homicidios por cada 100.000 habitantes), de 673 municipios, 
180 están libres de minas, y en comparación con cifras del año 2006, en 2017 se redujo en un $97 \%$ el número de víctimas, entre otras cifras.

En tercer término, acerca de la reincorporación social, de voces de la dirección del Centro de Análisis y Asuntos Públicos de las FARC, el proceso de reincorporación de los excombatientes avanza, pero con lentitud, lo que posiblemente se constituya en una fuente de desmotivación para los involucrados, si realmente tienen el interés de volver a incorporarse sanamente a la realidad social colombiana.

En cuarto término, la ONU (2017) informó que el cultivo de coca en el país sufrió un incremento del $52 \%$, pese a que el acuerdo de paz refiere la sustitución voluntaria con la creación del Programa Nacional Integral de Sustitución de Cultivos, pero los campesinos han denunciado que las autoridades realizan la erradicación forzada. Sobre este punto, el informe de la Fundación Paz y Reconciliación (2017) revela que el 50 \% de los cultivos se encuentra en diez municipios de cuatro departamentos colombianos: Nariño, Norte de Santander, Cauca y Putumayo. No obstante, una de las principales razones para realizar esta actividad es económica, Pero lo que para los pobladores representa una alternativa de ingresos ante las condiciones de pobreza en las que viven, para el mundo se convierte en uno de sus mayores flagelos.

Por otra parte, se ha visto desencadenada la presencia de la mujer en el proceso de paz, a través de grupos feministas, quienes se movilizaron al comienzo de las negociaciones para expresar que "la paz sin mujeres no va". Incluso, con la creación de la Subcomisión de Género, alcanzaron una representación de casi el 16 por ciento en la mesa de diálogo y la incorporación de un enfoque más equitativo e igualitario en el acuerdo. Sin embargo, en la actualidad han denunciado la falta de garantías en los derechos de las mujeres y de las minorías étnicas, como la seguridad y el respeto a sus territorios, en la implementación del proceso de paz en la nación.

No obstante todo lo planteado, alcanzar la paz, de acuerdo a Rodríguez (2014), no se restringe a conseguir acuerdos con las FARC. Hace falta un entorno político favorable y afrontar los desafíos a la implementación de los compromisos. Además, es necesario plantearse cómo se va a involucrar 
la población civil en el proceso de post-conflicto y cómo se va a reconstruir el tejido social y permitir la reintegración de los excombatientes.

De allí que el gobierno tiene que ser capaz de explicar y asegurar a la sociedad, los empresarios, la elite política y la comunidad internacional que para conseguir la paz y sus beneficios es necesario hacer inversiones a mediano y largo plazo. La justicia transicional y un cambio radical en la política social son parte de esas inversiones. Asimismo, hace falta un pacto político que supere la dialéctica entre negociar o luchar para concentrarse en construir, para insistir en la reconstrucción de la institucionalidad, el estado de derecho y la democracia.

\section{Acciones implementadas en la búsqueda de la negociación con el ELN para la construcción de la paz}

En América Latina, la tendencia en las relaciones entre países y los sujetos involucrados con sus actos, nacionales o extranjeros, ha debido estar fun- damentada en la integración, desde diferentes aristas políticas, jurídicas, sociales, económicas, culturales; buscando establecer vínculos o asideros reglamentarios basados en principios de cooperación, solidaridad, respeto, bien común, orden, sin obviar la necesaria soberanía de los pueblos.

No obstante, el devenir de la historia de Latinoamérica ha estado marcado por situaciones adversas que han desviado el camino de la paz. Tal es el caso de la generación de desmanes provenientes de la guerrilla, que se ha venido analizando, específicamente en Colombia, donde se ha vivenciado una confrontación por espacio de más de 50 años; tiempo este durante el cual se han realizado conversaciones en el intento por la paz, decretos de tregua, pero sin mayores logros; hasta que el cambio producido en la estrategia militar y la intensificación de su presencia en el territorio ubicado por la guerrilla, han impulsado a ésta a la mesa de negociación entre el gobierno de Colombia, las FARC, aunado al Ejército de Liberación Nacional (ELN).

Cabe considerar que en un primer paso a la creación de fundamentos políticos que agilicen una fórmula de negociación entre las fuerzas intervinientes, se ha demostrado que, aunque no esté vencida la guerrilla, no 
les es posible alcanzar el poder por medio de las armas. No obstante, esa tramitación equivale a considerar un acuerdo, encuadrado en un marco político estable, conveniente a los intervinientes, así como la adhesión, respaldo y conformidad de grupos políticos involucrados, oficiales o no, y el impacto o implicaciones en sus resultados.

Es así como Villarraga (2014), analizando el proceso de paz, haciendo un balance y perspectiva de los intentos habidos, hace un repaso sintético de los avances, las resistencias, las incoherencias, los ajustes, los vacíos y los desafíos pendientes en la búsqueda de una salida negociada al conflicto entre el estado y las guerrillas colombianas, afirmando que se plantea un buen balance en el proceso de paz entre el gobierno y las guerrillas.

Manifiesta asimismo que, en efecto existen aspectos dispuestos para completar los acuerdos con la FARC y se avance en la negociación con el ELN, quienes aún se mantienen, aunque la Fuerza Pública haya logrado debilitarlos y replegarlos. El esfuerzo militar de la primera le hapermitido retomar cierta iniciativa, pero su guerra es ahora de resistencia, y su perspectiva, una victoria estratégica. Por su parte el ELN, con menor potencial y posibilidades, se mantiene mediante una estrategia defensiva.

Sobre esa base, el gobierno de Colombia y el ELN iniciaron conversaciones de paz desde enero de 2017, apostando el gobierno a la construcción de la paz dentro de un marco legal que indujere la concordia. Al efecto, el gobierno ha autorizado varios encuentros entre los jefes de la FARC y del ELN con el objetivo de que los primeros informen detalles del acuerdo de paz y faciliten la negociación con el que ahora es el único grupo guerrillero que queda en Colombia, mostrándose este último, el ELN, receptivo a demarcar que los puntos sobre los cuales se basó el acuerdo con las FACR pueden ser objeto de mejoras sustanciales para ambas partes involucradas.

Incluso, el acuerdo de alto el fuego y de hostilidades, sorprendió al país porque fue pactado en los primeros meses del proceso de paz, pues en el caso de las FARC fue definido en la parte final de las negociaciones. Además, la tregua empezó en medio de grandes tensiones derivadas de una 
ofensiva del ELN contra la infraestructura petrolera, que causó la contaminación de ríos y quebradas por el derrame de petróleo a consecuencia de atentados con explosivos contra un oleoducto.

No obstante lo planteado, se plantea el análisis de la posibilidad de un acuerdo de paz con el ELN, ante lo cual, diversas son las expectativas, de apoyadores, pero también de detractores. Es así como, Celis (2018), especialista en temas de paz y posconflicto, manifiesta que un acuerdo con el ELN solo se logrará a través de la madurez en los planteamientos y nuevas realidades políticas emergidas de los mismos.

En efecto, se han realizado diversas y discretas mesas de diálogos y negociaciones entre el gobierno del presidente Santos y el ELN, pero estas temporalidades muestran que está es una negociación muy difícil; se abren diálogos, se suspende el proceso, se tensiona el conflicto, se abandona, se produce una distensión en el cese bilateral, todo lo cual evidencia incoherencias difíciles de superar. Incluso, la opinión ciudadana se vuelve más reticente a un proceso, no obstante tener poco espacio en el devenir nacional; y cada hecho de violencia, reafirma una extendida opinión que está afincada en la convicción de que pensar en un acuerdo negociado con el ELN es misión imposible.

De la misma manera, es de todos conocido que el tiempo delgobierno del presidente Santos está en cuenta regresiva, lo que implica que las condiciones para que este proceso avance pasan por reactivar la mesa, tarea nada fácil, en lo cual hay terceros trabajando, con cuya discreción y eficiencia sea posible lograrlo. Salir de un alzamiento armado no es decisión fácil: el peso de los años de trasegar la acción armada, la convicción de que no hay garantías para competir, la rutina de manejar territorios y controlar economías, representa una carga difícil de negociar a través de una acción legal.

Llegar a la convicción de que las armas no son presente, ni futuro, es una construcción de autonomía de las organizaciones que han agenciado una acción política con armas. El ELN no es la excepción, tienen dudas, cálculos políticos, escepticismo, rutinas arraigadas en su resistencia armada sin rumbo de futuro; y desde su interior, en la complejidad de una estruc- 
tura clandestina, que disminuida y todo sigue siendo un aparato organizado, con arraigo en comunidades y una historia de más de medio siglo, trasegando territorios, participando de conflictos e insistiendo en que no hay garantías para la acción legal, en lo cual la evidencia de violencia sistemática contra líderes, le da en parte la razón, no hay plenas garantías para la acción legal en muchos territorios de esta Colombia de atropellos y matones, no hay estado que los controle y los sancione de manera efectiva.

La otra cara de esta tragedia es que un largo conflicto armado tiene llena de rabia a la sociedad, que no cree ni comparte la acción armada y de manera ampliamente mayoritaria, hace por lo menos dos décadas ha sido categórica en un no más a la violencia como instrumento de acción política. El clima político de una continuidad de violencias regionales, el desorden y la pugnacidad que produce las inmensas rentas de las economías ilegales, llámese narcotráfico, minería ilegal o lo que sea que se controle con violencias y coerción, sumado a una lenta y difícil implementación del acuerdo firmado con las FARC y el desangre visible de los líderes, nada de esto anima al ELN y lo refuerza en sus dudas del camino negociado.

Confirma Celis (2018) que razones para mantenerse en la resistencia armada habrá siempre, razones para el cierre de la resistencia armada igualmente abundan, son construcciones políticas y los actores que protagonizan estas apuestas son los únicos que pueden definir su rumbo, de manera autónoma, nadie les puede imponer nada, son las organizaciones con sus dirigentes y su capacidad de persuasión en un rumbo u otro el que define el camino, allí está el ELN, con sus retos de presente y futuro, a quienes se debe motivar a persistir en el camino negociado, que se concentre en él, que tensionar el conflicto aleja la participación y la construcción de nuevas realidades, pero en ultimas será el propio ELN quien decida su caminar.

Por ahora se tiene una mesa congelada que hay que reactivar y un gobierno en sus postrimerías que quiere avanzar, junto a unas comunidades y unas regiones que no aguantan más violencia. Pero, se ha de apostar a la paz negociada en Colombia. De allí que el proceso de pacificación entre el estado colombiano y el ELN se vislumbra como una ventana abierta a la concordia, al apaciguamiento de los daños e infortunios cometidos por personeros de la guerrilla colombiana basados en su desesperación por 
alcanzar el poder, con el interés estratégico de la defensa de Colombia, de la tutela de los ciudadanos, en la búsqueda como consecuencia, de la tranquilidad social y el bien común, como fin último y primario a ser perseguido por el gobierno nacional en sus actos.

\section{La construcción de la paz en Colombia}

La Construcción de la Paz (CP) es un proceso dinámico, complejo, diverso, el cual se caracteriza de acuerdo al Instituto de Estudios sobre conflicto y acción humanitaria (IECAH, 2010), como "el conjunto de acciones (en el corto, mediano y largo plazo) que permiten a una sociedad prevenir, gestionar y resolver el conflicto a través de sus propias capacidades sin recurrir al uso de la violencia” (p. 1). Si bien esta definición implica un comportamiento de actores harto exigente, no menos cierto es que es posible visualizar a Colombia en este marco de armonía exigible para cualquier sociedad del orbe.

Ello, porque después de más de cinco (5) décadas de cruenta realidad, el país requiere verse envuelto en una gestión que le permita desenvolverse como sociedad de un modo sostenible, sustentable, con el fin de optimizar el manejo de los diversos recursos que le permita la supervivencia y el manejo de recursos para las generaciones de relevo. Esto es plausible si se produce una evolución integral de la ciudadanía colombiana como eje fundamental para articular acciones en los diversos contextos:

En el terreno social, fomentando una cultura para la vida, que incluya actividades como la prevención de conflictos, el mantenimiento de paz. En el ámbito económico, partiendo del otorgamiento de seguridad social a los habitantes, propios y extraños de Colombia, lo que involucra la garantía de la salud y requiere asegurar protección en contingencias de maternidad, paternidad, enfermedad, invalidez, enfermedades catastróficas, discapacidad, necesidades especiales, riesgos laborales, pérdida de empleo, desempleo, vejez, viudedad, orfandad, vivienda, cargas derivadas de la vida familiar y cualquier otra circunstancia de previsión social.

En la perspectiva política, mediante la creación de sistemas de alerta temprana, reforma del sector de seguridad, consolidación de autoridades 
legítimas, como mecanismos que permitan fortalecer las capacidades socioeconómicas o políticas para promover una paz sostenible e inclusiva.

Esa misma consolidación de la paz debe constituirse en una estrategia, un camino para alcanzar la estabilidad estructural y su correspondiente nivel de Seguridad Humana, en el afán de eliminar las causas estructurales de los conflictos violentos para fortalecer armónicamente las sociedades y su convivencia pacífica.

Esto ha sido un esfuerzo gubernamental de Colombia de varias décadas, realizado por sujetos diversos, emprendedores, colaboradores, innovadores, gente de paz... pero también influenciada por opositores, por detractores, que buscan en el conflicto la satisfacción a sus bajas necesidades afectivas e incluso espirituales, y que canalizan sus metas solo mediante el afán de poder -que no de autoridad, ni de liderazgo efectivo-, sino basado en tareas propias de un colaboracionista, entendido el término como atribuido a aquel que auxilia o coopera con el enemigo, bajo una forma de traición, aquel individuo, funcionario o no, que coopera con las fuerzas de ocupación enemiga, despreciando sus aciagas consecuencias.

\section{Conclusiones}

En el año 2016, habiéndose firmado en Colombia el acuerdo de pacifica- ción con la FARC, se le dio legitimidad a los cinco (5) puntos acordados y establecidos entre el gobierno colombiano y ese grupo irregular. Con tales fines, la FARC le dio un supuesto respaldo al acuerdo, haciendo entrega, de las armas existentes en su poder, y de personas secuestradas, desligán- dose de la producción, laboratorio y envío de drogas a diversas partes del mundo, liberándose de prácticas ilegales con el narcotráfico, entre otras acciones posibles.

Por su parte, el gobierno colombiano debía, mediante los Jueces de paz, decidir qué grupo de personas cumplían con los requisitos para la libertad condicionada, y aquellos que debían cumplir una condena por un tiempo mínimo, de acuerdo a la gravedad de los hechos ejecutados. Además, se les debía otorgar curules a los guerrilleros en la Cámara del Senado de 
Colombia, además de opciones a candidaturas presidenciales, medidas estas que aún siguen siendo rechazadas por algunos dirigentes políticos relevantes.

De igual forma, el gobierno debía atender a los rebeldes entregados para ser reinsertados a la sociedad, resolver la entrega de tierras acordada, suministrando capacitación para el manejo de los procesos necesarios, a la vez que permitiendo la creación de organizaciones de economía social, solidaria, sostenible, de innovación, capaces de apoyar la rehabilitación social de las personas incursas en delitos; debiendo proveerles de seguridad social, utilizando a tales fines el dinero proveniente del narco y de los demás actos criminales cometidos por ellos.

Sin embargo, organizaciones mundiales y las FARC afirman lo lento del proceso de ejecución del acuerdo, el incumplimiento de lo pactado, lo que derivaría en una suerte de negligencia de las partes, atribuyéndose al gobierno, sobre todo, la ausencia de nombramiento de jueces para la justicia transicional, y a las FARC el incremento de los cultivos de coca en el país.

Ahora bien, en aras de darle continuidad a tales proyectos de pacificación, se continúan generando encuentros de diálogo, primariamente en Cuba, ahora en Ecuador, como territorio negociador entre el gobierno colombiano y los rebeldes, planteando discusiones que pudieran haber llevado a algunos convencimientos precisos, en el afán del ELN de mejora de los puntos acordados en el tratado de paz con la FARC.

De lograr tales acuerdos, la pacificación tendría una ventana abierta al mundo para servir de prototipo en aras de lograr la construcción de la paz, la armonía mundial, una vez alcanzado un diálogo participativo, sincero, que permita el logro de los objetivos propuestos; no obstante estar observando en los últimos días la matanza de líderes sociales en un número mayor a un ciento, la incoherencia en las propuestas y en las soluciones dadas, la soberbia y beligerancia de algunos actores implicados, la hostilidad de representantes del gobierno, y de algunos miembros del ELN, que resulta inquietante a la luz de la verdad. 


\section{Referencias bibliográficas}

Alto Comisionado de las Naciones Unidas para los Refugiados (Acnur, 2018). Acnur denuncia asesinatos de líderes sociales en Colombia. Disponible en https://www.telesurtv.net/news/Acnur-denuncia-asesinatos-de-lideres-sociales-en-Colombia-20171117-0055.html

Ander-Egg, E. (2009). Métodos y Técnicas de Investigación Social. Técnicas para la recogida de d:

Hvanitas.

Arias, F. (2012). Mitos y Errores en la Elaboración de Tesis y Proyectos de Investigación. Caracas: Episteme.

Celis, L. E. (2018). Análisis: Es posible un acuerdo de par con el ELN. Disponible en https://www.elespectador.com/noticias/paz/analisis-es-posible-unacuerdo-de-paz-con-el-eln-articulo-738214.

Chernick, M. (2012). Acuerdo posible: solución negociada al conflicto armado colombiano (3era. edición). Bogotá: Aurora.

Estraño, A. J. (2009). La Técnica de la Investigación Jurídica Dogmática (II). UPEL Maracay. Disponible en http://www.entorno-empresarial.com/imprimir. php? id $=2739$.

Fundación Paz y Reconciliación (2017). En: Qué se ha cumplido del acuerdo de paz en Colombia. Disponible en https://www.telesurtv.net/news/Que-seha-cumplido-del-Acuerdo-de-Paz-de-Colombia-en-un-ano-201711230075.html

González Muñoz, C. A. (2015). Diálogos de paz Gobierno-FARC-EP y las oportunidades para la paz en Colombia. Estudios Políticos, núm. 46, enerojunio, 2015, pp. 243-261. Instituto de Estudios Políticos. Medellín, Colombia. Disponible en http://www.redalyc.org/articulo.oa?id=16433765013.

Instituto de Estudios sobre conflicto y acción humanitaria (IECAH, 2010). Construcción de la paz. Disponible en https://www.iecah.org/index.php/investigacioncp.

Martínez Miguélez, M. (2012). Investigación cualitativa. Madrid. Editorial Trillas.

Misión de la Organización de las Naciones Unidas (ONU, 2017). Misión de la $\mathrm{ONU}$ en Colombia. Disponible en https://unmc.unmissions.org $/ \mathrm{misi} \% \mathrm{C} 3 \% \mathrm{~B} 3 \mathrm{n}$-de-la-onu-finaliza-actividades-de-inhabilitaci $\% \mathrm{C} 3 \% \mathrm{~B} 3 \mathrm{n}$-del-armamento-de-las-farc-ep

Nava, H. (2002). Metodología de la investigación. Venezuela, Ediluz. 
Observatorio de Seguimiento a la Implementación del Acuerdo de Paz (2018). Balance del acuerdo de paz. Disponible en https://cnnespanol. cnn.com/2018/01/05/como-va-la-paz-en-colombia-santos-y-farc-hacenbalance-de-la-implementacion-del-acuerdo/

Olave, G. (2013). El proceso de paz en Colombia según el estado y la FARC-Ep, Artículo publicado en la revista Discurso \& Sociedad, Volumen 7 de la Universidad de Buenos Aires. Disponible en http://www.dissoc.org/ediciones/v07n02/DS7(2)Olave.pdf.

Rodríguez Pinzón, E. (2014). Los diálogos de paz en Colombia, avances y prospectiva. España. Revista del Real Instituto Elcano. Disponible en http://www.realinstitutoelcano.org/wps/portal/web/rielcano_es/contenido?WCM_GLOBAL_CONTEXT=/elcano/elcano_es/zonas_es/america+latina/ari18-2014-rodriguezpinzon-+dialogos-paz-colombia-avancesprospectiva

Sabino, C. (2010). El Proceso de Investigación. Nueva Edición Actualizada. Editorial Panapo de Venezuela. Caracas. Venezuela.

Villarraga Sarmiento, Á. (2014). El proceso de paz: balance y perspectiva 20142015. Artículo en Revista Razón pública, Colombia. Directivo del Centro Nacional de Memoria Histórica, integrante de la Fundación Cultura Democrática, catedrático universitario. Disponible en http://www.razonpu blica.com/index.php/conflicto-drogas-y-paz-temas-30/8159-el-proceso-depaz-balance-y-perspectiva-2014-2015.html 